\title{
Ethanol and Methanol Concentration in Commonly Used Brands of Ma-al-shaeer in Iran: Estimation of Dietary Intakes and Risk Assessment
}

\author{
Kobra Shirani', Hassan Badie Bostan', Ashkan Baroti', Mohammad Hassanza- \\ deh$^{2}$, Zahra Khashyarmanesh², Hamideh Moalemzadeh Haghighi², Gholamreza \\ Karimi ${ }^{1,3 *}$ \\ ${ }^{1}$ Department of Pharmacodynamy and Toxicology, School of Pharmacy, Mashhad University of Medical Sciences, Mashhad, Iran \\ ${ }^{2}$ Deparment of Medicinal Chemistry, School of Pharmacy, Mashhad University of Medical Sciences, Mashhad, Iran \\ ${ }^{3}$ Pharmaceutical Research Center, Pharmaceutical Technology Institute, Mashhad University of Medical Sciences, Mashhad, Iran
}

\section{Key Words}

ethanol, methanol, Ma-al-shaeer, non-alcoholic beer, gas chromatography, risk assessment.

\section{Abstract}

Objectives: Ma-al-shaeer is a popular beverage in Islamic countries. The aim of this study was to determine the concentrations of methanol and ethanol in most consumed brands of Ma-al-shaeer in Iran.

Methods: Eighty-one Ma-al-shaeer samples which commonly used in Iran were provided. Methanol and ethanol contents were determined by gas chromatography with flame ionization detector.

Results: The mean methanol concentrations in Iranian and foreign brands was $129.84 \pm 205.38 \mathrm{mg} / \mathrm{L}$ and $110.157 \pm 135.98 \mathrm{mg} / \mathrm{L}$, respectively. Although mean ethanol contents of Iranian brands was $1.2 \pm 2.41 \mathrm{mg} / \mathrm{L}$, ethanol level in foreign ones was lower than LOQ.

Conclusion: Since the most Ma-al-shaeer brands had methanol pollution at different levels establishment of a

Received: Jan 09, 2018 Reviewed: Jul 02, 2018 Accepted: Aug 02, 2018

$(0$ This is an Open-Access article distributed under the terms of the Creative Common Attribution Non-Commercial License (http://creativecommons.org/licenses/by-nc/4.0/) which permits unrestricted noncommercial use, distribution, and reproduction in any medium, provided the original work is properly cited.

(2) This paper meets the requirements of KS X ISO 9706, ISO 9706-1994 and ANSI/NISO Z39.48-1992 (Permanence of Paper). definitive relationship between the methanol content and toxicological effects seem to be vital. EDI of methanol for Iranian people through consumption of Maal-shaeer was determined $0.023 \mathrm{mg} / \mathrm{kg}$ bw/day.

\section{Introduction}

Beer is one of the most favorable beverages in the world. Owing to adverse effects of alcoholic beer on athletes, those with cardiovascular diseases, and pregnant women, there has been increasing tendency to consume non-alcoholic beer $[1,2]$. Findings have shown the beneficial effects of different components of beer [3]. Phenolic compounds in beer exhibited useful biological effects including elevation of plasma antioxidant capacity, prevention of atherosclerosis and cancer, and modulation of enzymatic activity (i.e. superoxide dismutase and glutathione peroxidase) [4, 5]. These elements not only inhibit the oxidation of low density lipoprotein (LDL) but also affect activation of transcription factors and gene expression [6, 7]. Lysine, an essential amino acid in non-alcoholic beer, revealed anxiolytic effect in human. This is refers to partial 5HT4 antagonist role of L-lysine [8]. Recently, sedative effect of alcohol-free beer in healthy female

"Corresponding Author

Gholamreza Karimi. Pharmaceutical Research Center, Institute of Pharmaceutical Technology, Mashhad University of Medical Sciences, Mashhad, Iran.

Tel: + 98-511-882-3255 Fax: +98-511-882-3251

E-mail: KarimiG@mums.ac.ir 
nurses was reported [9].

Ma-al-shaeer, a non-alcoholic beer, is among the most consumed drinking in the world [10]. Nowadays, different methods are developed for production of non-alcoholic malt or low alcohol beers. Fermentation with saccharomyces strain, dialysis, and reverse osmosis are example of them. It should be note that production of alcohol (i.e. methanol and ethanol) is inevitable in most techniques [11]. Due to mass production of it, quality assessment of this product is an important issue.

Methanol, as a colorless liquid, is freely miscible with water and easily cross the blood-brain barrier. Along with lethal dose of 1-2 mL/kg, methanol poisoning is common in clinical practice. Death and blindness have been shown with as low as $0.1 \mathrm{~mL} / \mathrm{kg}$. After oral intake, methanol is absorbed rapidly and metabolized in liver. Formic acid, a main toxic metabolite of it, disrupts cytochrome $\mathrm{C}$ oxidase activity. Methanol poisoning can result in optic nerve lesion, hypotension, CNS damage and anion gap metabolic acidosis [12].

Similarly, it has been shown that ethanol consumption is correlated with violence, cirrhosis, stroke, and poisoning. In addition, association between ethanol use and malignancies such as liver, breast, and colon cancers are exhibited. World Health Organization (WHO) estimated that alcohol is responsible to approximately 2.5 million deaths each year [13]. On the other hand, ethanol consumption, selling, and transport is prohibited in Islamic sources (i.e. Qur'an) $[14,15]$. Hence, in current study, we aimed to determine the levels of ethanol and methanol in commonly used brands of Ma-al-shaeer in Iran.

\section{Material and Methods}

\subsection{Sample collection}

Eight most used brands of Ma-al-shaeer, comprising of five Iranian brands and three foreign ones were collected from different markets in Iran. Within a given brands, the most popular flavors were selected. Then, three different samples from each flavor were provided. Finally, eighty one most commonly used Ma-al-shaeer samples were tested.

\subsection{Reagents}

Methyl alcohol and ethyl alcohol were obtained from Sigma-Aldrich (Steinheim, Germany). 1-butanol and 2-propanol were purchased from Merk (Darmstadt, Germany). Distilled deionized water (DDW) was supplied from a Millipore Milli-Q water system (Bedford, MD). All other chemicals and reagents were of the highest available purity and used as purchased.

\subsection{Chemical Analysis}

Involving GC-PFPD, analyte concentrations were determined. Analysis was carried out on a Varian CP-3800 GC directly coupled to a Varian PFPD detector (Varian, Inc., Lexington, Massachusetts, USA). The GC column was a DB-5 capillary column $(0.25-\mu \mathrm{m}$ film thickness, $0.32 \mathrm{~mm}$ ID $\times 30 \mathrm{~m}$ in length), obtained from J\&W Scientific (Folsom, California, USA).

The operating conditions were as follows: the carrier gas was N2 with a linear velocity of $30 \mathrm{~mL} / \mathrm{min}$ and air flow rate of $300 \mathrm{~mL} / \mathrm{min}$. In isothermal state, the injection port, column and detector temperatures were 65 and $200{ }^{\circ} \mathrm{C}$, respectively. Along with Split ratio 20, retention time was 12 minutes.

\subsection{Evaluation of Accuracy and repeatability}

Quantification was performed by the use of external calibrations which were obtained with methanol and ethanol solutions at six concentration levels. The r2valuesforthecalibrationlinesforthemethanolandethanolwerecalculated0.9924and0.9975, respectively.InterdayandIntradaytestswereemployedtoevaluateaccuracyandrepeatability.

\subsection{Tolerable daily intake (TDI) and estimated daily intake (EDI)}

The tolerable daily intake (TDI) is indicative of safe exposure levels and is used to predict the amount of chemical substances, ingested over a lifetime without important risk.

The daily intake of methanol not only depends on daily food consumption but also related to methanol levels in foods. Body weight is another key factor can affect the tolerance of pollutants. Based on upon factors estimated daily intake (EDI) can be determined. Consequently, According to the following equation (1), EDI was calculated:

$$
E D I=\frac{E F \times E D \times F I R \times C}{\mathrm{WAB} \times \mathrm{TA}}
$$

Where EF is exposure frequency (365 days/year); ED is the exposure duration (70 years), equivalent to the average lifetime; FIR is the food ingestion rate $(13.7 \mathrm{~mL} /$ person/day); $\mathrm{C}$ is the mean methanol concentration in Maal-shaeer $(\mathrm{mg} / \mathrm{L})$; WABis the average body weight $(70 \mathrm{~kg})$ and TA is the averaging exposure time for non-carcinogens (365 days/year x ED) [16].

\subsection{Statistical Analysis}

The values are expressed as means \pm SD. ANOVA (analysis of variance) and the Tukey posttest were employed to determine significant differences in the data of various groups. $\mathrm{P}$ values less than 0.05 were considered significant. 
Table 1 LOD and LOQ values (mg/L) of the analytical method for methanol (MeOH) and ethanol (EtOH).

\begin{tabular}{lll}
\hline Analytes & LOD & LOQ \\
\hline $\mathrm{MeOH}$ & 5 & 25 \\
$\mathrm{EtOH}$ & 2.5 & 10 \\
\hline
\end{tabular}

Table 2 Interday validation of method using six different concentrations (mg/L)

\begin{tabular}{cccccccc}
\hline \multicolumn{7}{c}{ Interday validation } \\
\hline \multicolumn{7}{c}{ Concentration $(\mathrm{n}=6)$} \\
Analytes & & 50 & 75 & 100 & 125 & 150 & 200 \\
$\mathrm{MeOH}$ & $\mathrm{Mean} \pm \mathrm{SD}$ & $0.198 \pm 0.001$ & $0.407 \pm 0.0025$ & $0.630 \pm 0.0012$ & $0.763 \pm 0.0008$ & $0.950 \pm 0.009$ & $1.26 \pm 0.012$ \\
& $\% \mathrm{CV}$ & 0.655 & 0.615 & 0.15 & 0.104 & 0.094 & 0.995 \\
$\mathrm{EtOH}$ & $\mathrm{Mean} \pm \mathrm{SD}$ & $0.354 \pm 0.0018$ & $0.524 \pm 0.0012$ & $0.729 \pm 0.0015$ & $0.918 \pm 0.001$ & $1 \pm .0 .011$ & $1.31 \pm 0.0222$ \\
& $\% \mathrm{CV}$ & 5.07 & 2.29 & 2.05 & 1.1 & 1.07 & 1.706 \\
\hline
\end{tabular}

Abbreviations: $\mathrm{MeOH}$ : methanol, EtOH: ethanol, SD: standard deviation, $\mathrm{CV}$ : coefficient of variation

Table 3 Interday validation of method using six different concentrations (mg/L)

\begin{tabular}{cccccccc}
\hline \multicolumn{7}{c}{ Interday validation } \\
\hline \multicolumn{7}{c}{ Concentration $(\mathrm{n}=6)$} \\
\hline \multirow{2}{*}{ Analytes } & & 50 & 75 & 100 & 125 & 150 & 200 \\
$\mathrm{MeOH}$ & $\mathrm{Mean} \pm \mathrm{SD}$ & $0.204 \pm 0.0144$ & $0.419 \pm 0.0226$ & $0.628 \pm 0.0238$ & $0.759 \pm 0.413$ & $0.936 \pm 0.05$ & $1.26 \pm 0.0954$ \\
& $\% \mathrm{CV}$ & 0.037 & 5.379 & 5.789 & 5.422 & 5.312 & 7.571 \\
$\mathrm{EtOH}$ & $\mathrm{Mean} \pm \mathrm{SD}$ & $0.347 \pm 0.0396$ & $0.564 \pm 0.044$ & $0.752 \pm 0.0439$ & $0.956 \pm 0.069$ & $1.708 \pm .0 .079$ & $1.47 \pm 0.203$ \\
& $\% \mathrm{CV}$ & 11.40 & 7.79 & 5.83 & 6.89 & 7.74 & 1.90 \\
\hline
\end{tabular}

Abbreviations: $\mathrm{MeOH}$ : methanol, EtOH: ethanol, SD: standard deviation, $\mathrm{CV}$ : coefficient of variation

Table 5 The levels of methanol (MeOH) and ethanol (EtOH) content (mg/L) in defferent foreign Ma-al-shaeer brands.

\begin{tabular}{llll}
\hline Brands & Flavor & Analytes & Mean \pm SD \\
\hline Bavaria & Peach & $\mathrm{MeOH}$ & $<25$ \\
& & $\mathrm{EtOH}$ & $<10$ \\
& Apple & $\mathrm{MeOH}$ & $<25$ \\
& & $\mathrm{EtOH}$ & $<10$ \\
& Pomegranate & $\mathrm{MeOH}$ & $<25$ \\
& & $\mathrm{EtOH}$ & $<10$ \\
& Malt & $\mathrm{MeOH}$ & $39.44 \pm 9.17$ \\
& Malt & $\mathrm{MeOH}$ & $<10$ \\
Efes & Malt & $\mathrm{EtOH}$ & $18.2 \pm 12.97$ \\
& Malt & $\mathrm{MeOH}$ & $<10$ \\
Baltika & & EtOH & $302.24 \pm 126.75^{*}$ \\
& & & $<10$ \\
\hline
\end{tabular}

Abbreviations: *: amount higher than legal limit 
Table 4 The levels of methanol $(\mathrm{MeOH})$ and ethanol (EtOH) content (mg/L) in different Iranian Ma-al-shaeer brands.

\begin{tabular}{|c|c|c|c|}
\hline Brands & Flavor & Analytes & Mean \pm SD \\
\hline \multirow[t]{8}{*}{ Bit malt } & \multirow[t]{2}{*}{ Equatorial } & $\mathrm{MeOH}$ & $26.6 \pm 0.50$ \\
\hline & & $\mathrm{EtOH}$ & $<10$ \\
\hline & \multirow[t]{2}{*}{ Apple } & $\mathrm{MeOH}$ & $30.24 \pm 2.36$ \\
\hline & & $\mathrm{EtOH}$ & $<10$ \\
\hline & \multirow[t]{2}{*}{ Lemon } & $\mathrm{MeOH}$ & $28.35 \pm 2.26$ \\
\hline & & $\mathrm{EtOH}$ & $<10$ \\
\hline & \multirow[t]{2}{*}{ Malt } & $\mathrm{MeOH}$ & $35.17 \pm 2.98$ \\
\hline & & EtOH & $<10$ \\
\hline \multirow[t]{20}{*}{ Istak } & \multirow[t]{2}{*}{ Peach } & $\mathrm{MeOH}$ & $<25$ \\
\hline & & $\mathrm{EtOH}$ & $<10$ \\
\hline & \multirow[t]{2}{*}{ Cantaloupe } & $\mathrm{MeOH}$ & $32.61 \pm 2.86$ \\
\hline & & $\mathrm{EtOH}$ & $<10$ \\
\hline & \multirow[t]{2}{*}{ Strawberry } & $\mathrm{MeOH}$ & $10.25 \pm 14.51$ \\
\hline & & EtOH & $<10$ \\
\hline & \multirow{2}{*}{ Mango } & $\mathrm{MeOH}$ & $30.40 \pm 1.95$ \\
\hline & & EtOH & $<10$ \\
\hline & \multirow{2}{*}{ Pineapple } & $\mathrm{MeOH}$ & $19.81 \pm 14.04$ \\
\hline & & $\mathrm{EtOH}$ & $<10$ \\
\hline & \multirow{2}{*}{ Lemon } & $\mathrm{MeOH}$ & $<25$ \\
\hline & & $\mathrm{EtOH}$ & $<10$ \\
\hline & \multirow[t]{2}{*}{ Coffee } & $\mathrm{MeOH}$ & $18.24 \pm 13.90$ \\
\hline & & $\mathrm{EtOH}$ & $<10$ \\
\hline & \multirow[t]{2}{*}{ Pomegranate } & $\mathrm{MeOH}$ & $9.70 \pm 13.72$ \\
\hline & & $\mathrm{EtOH}$ & $<10$ \\
\hline & \multirow{2}{*}{ Malt } & $\mathrm{MeOH}$ & $8.59 \pm 13.15$ \\
\hline & & $\mathrm{EtOH}$ & $<10$ \\
\hline & \multirow[t]{2}{*}{ Equatorial } & $\mathrm{MeOH}$ & $29.40 \pm 5.15$ \\
\hline & & $\mathrm{EtOH}$ & $<10$ \\
\hline \multirow[t]{8}{*}{ Hey day } & \multirow[t]{2}{*}{ Peach } & $\mathrm{MeOH}$ & $13.73 \pm 19.45$ \\
\hline & & $\mathrm{EtOH}$ & $<10$ \\
\hline & \multirow{2}{*}{ Lemon } & $\mathrm{MeOH}$ & $18.93 \pm 13.39$ \\
\hline & & $\mathrm{EtOH}$ & $<10$ \\
\hline & \multirow[t]{2}{*}{ Equatorial } & $\mathrm{MeOH}$ & $19.73 \pm 13.95$ \\
\hline & & EtOH & $<10$ \\
\hline & \multirow[t]{2}{*}{ Lemon-Mint } & $\mathrm{MeOH}$ & $35.77 \pm 11.72$ \\
\hline & & $\mathrm{EtOH}$ & $<10$ \\
\hline \multirow[t]{2}{*}{ Petrovich } & \multirow[t]{2}{*}{ Malt } & $\mathrm{MeOH}$ & $540.27 \pm 157.546^{*}$ \\
\hline & & $\mathrm{EtOH}$ & $<10$ \\
\hline \multirow[t]{8}{*}{ Holstein } & Peach & $\mathrm{MeOH}$ & $35.39 \pm 5.54$ \\
\hline & & $\mathrm{EtOH}$ & $<10$ \\
\hline & Apple & $\mathrm{MeOH}$ & $55.14 \pm 2.17$ \\
\hline & & $\mathrm{EtOH}$ & $16.26 \pm 22.99$ \\
\hline & Lemon & $\mathrm{MeOH}$ & $40.56 \pm 0.98$ \\
\hline & & $\mathrm{EtOH}$ & $16.42 \pm 3.22$ \\
\hline & Malt & $\mathrm{MeOH}$ & $32.59 \pm 3.08$ \\
\hline & & $\mathrm{EtOH}$ & $<10$ \\
\hline
\end{tabular}

Abbreviations: * amount higher than legal limit 


\section{Results}

\subsection{Calibration}

Calibration curves were obtained by use of 6 different concentrations of each analyte including 50, 75, 100, 125, 15 and $200 \mathrm{mg} / \mathrm{L}$, separately. In the range of 50 to 200 $\mathrm{mg} / \mathrm{L}$, response versus the amount of alcohol injected showed a good linearity. LOD (limit of detection) and LOQ (limit of quantification) values of analytical method are shown in table 1.

Ruggedness of method and instrument were assessed using the intra- and interday variance. To achieve this, six different concentration were prepared and injected to the GC. Results are shown in tables 1 and 2.

\subsection{Determination of alcohol content in samples}

Based on GC chromatograms (figures1 and 2), methanol and ethanol concentrations were calculated. Results are shown in table 4 and 5 . Results showed that mean methanol concentration in Iranian and foreign brands were $129.48 \pm 205.34$ and $110.15 \pm 135.98 \mathrm{mg} / \mathrm{L}$, respectively. Statistical analysis showed that there is no significat difference between Iranian and foreign brands $(\mathrm{P}=0.889)$.

When Iranian brands were compared together, it was found that malt flavor of Petrovich brand contains the highest amount of methanol $(540.27 \pm 157.546 \mathrm{mg} / \mathrm{L})$. In addition, among the foreign ones malt flavor of Baltika brand contains the highest methanol concentration $(302.24 \pm 75.126 \mathrm{mg} / \mathrm{L})$. Although mean ethanol contents of Iranian brands was $1.2 \pm 2.41 \mathrm{mg} / \mathrm{L}$, ethanol level in foreign ones was lower than LOQ. Ethanol levels in apple and lemon flavors of Holstein brand were 16.26 \pm 22.99 and $16.41 \pm 3.22 \mathrm{mg} / \mathrm{L}$, respectively. No significant difference was observed when mean ethanol concentrations of Iranian brands compared with that of foreigns.

\section{Discussion}

In the current study, we determined the methanol and ethanol contents in different brands of Ma-al-shaeer available in Iran. Results of this work revealed that approximately all brands are contaminated with methanol at different levels. Fortunately, ethanol concentrations were lower than Maximum Residues Levels.

Legal definition for alcohol-free beer may different from country to country. Iran, Germany, and England accepted $0.5 \%(\mathrm{v} / \mathrm{v})$ as maximum ethanol level. However, US and Arabic countries determined $0.05 \%(\mathrm{w} / \mathrm{v})$ and $0.1 \%(\mathrm{v} / \mathrm{v})$, respectively [17].

In one study, ethanol and methanol contents of non-alcoholic beer samples were determined. Findings were revealed that methanol and ethanol concentration of classic Delester samples were $19.3 \pm 1.34$ and $21.8 \pm 1.22 \mu \mathrm{g} / \mathrm{L}$, respectively. Although methanol content in the Birell brand was $97.7 \pm 3.76, \mu \mathrm{g} / \mathrm{L}$, ethanol level was lower than detection range $(\mathrm{LOD}=2.5 \mu \mathrm{g} / \mathrm{L})[18]$. Employing gas chroma- tography, a rapid and sensitive method was developed for determination of ethanol in alcohol- free beverages and fruit juices. Herein, five brands of beer, four brands of apple juice, and seven brands of grape juices were analyzed. It was revealed that ethanol content is ranging from $0.009 \%$ to $0.385 \% \mathrm{v} / \mathrm{v}$ [19]. In another study, Hämmerle et al. provided a biosensor to determine alcohol (including ethanol and methanol) concentrations in apple juices. The sensing system was based on amperometric detection method and catalytic activity of alcohol oxidase. They showed that alcohol content of three apple juices were in the range $0.30-0.67 \mathrm{~g} / \mathrm{L}$. When these findings are compared together, it was observed that in some cases ethanol contents are higher than permissive levels. Although almost all products are contain ethanol level lower than legal limits, these products are not actually alcohol- free.

Result of our study is in accordance with these findings and all Ma-al-shaeer brands contained ethanol levels in permissive ranges.

American standard is permitted $120-460 \mathrm{mg} / \mathrm{L}$ of methanol in canned and fresh juices [20]. In addition, International Office of Vine and Wine (OIV) sets $150 \mathrm{mg} / \mathrm{L}$ as a maximum acceptable limit for methanol in white wines. The maximum allowable level of methanol recommended by the Iranian standard is $100 \mathrm{mg} / \mathrm{L}$ in the herbal distillates [21]. In this study, malt flavor of Petrovich and Baltika brands contained methanol in excess from standard.

Possner et al. determined the methanol content in fruit juices and nectars by GC-MS. In this study apple, pear, grape, elderly berry and multivitamin juices and pear, cherry, and black currant nectars were analyzed. Results showed that the highest methanol concentrations were found in black currant nectars and elderly berry Juices (160.5 and $149.5 \mathrm{mg} / \mathrm{L}$, respectively) [22]. Using spectrophotometry, Karimi et al. evaluated the amount of methanol in ten plant water. Their findings revealed that the highest methanol level was in dill distillate water (1477.7 \pm $23.8 \mathrm{mg} / \mathrm{L}$ ). However, Egyptian willow water samples contained minimum methanol content $(79.4 \pm 3 \mathrm{mg} / \mathrm{L})$ [23]. Wu et al. quantified methanol content in fresh fruit juices by means of methanol oxidase in combination with basic fuchsin. Methanol content in carrot, tomato, and papaya were determined to contain 36,42 , and $38 \mathrm{mg} / \mathrm{L}$, respectively [24].

Methanol is present in vegetable and fruit juice and related product. Pectin, a heteropolysaccharide component in the cell wall, composed of linear chains of a-1, 4-galacturonic acids. In nature, usually carboxyl groups of galacturonic acid are esterified with methanol. During fruit and vegetable process, enzymatic activities (i.e. Pectinesterase) are resulted in methanol and pectin release. Hence, methanol is found in those product bonded and freely. On the other hand, fermentation of cellulose may lead to methanol production [21, 22]. Different factors including type of yeast strain, fruit varieties and species and oenological practices can influence methanol level. In addition, various process of food production in different factories is another key factor influence methanol concentration in final product [22]. High methanol levels in different Ma-alshaeer brands may illustrated by these factors. Methanol is poisonous volatile liquid which potentially can produce 
Maashaeer figure

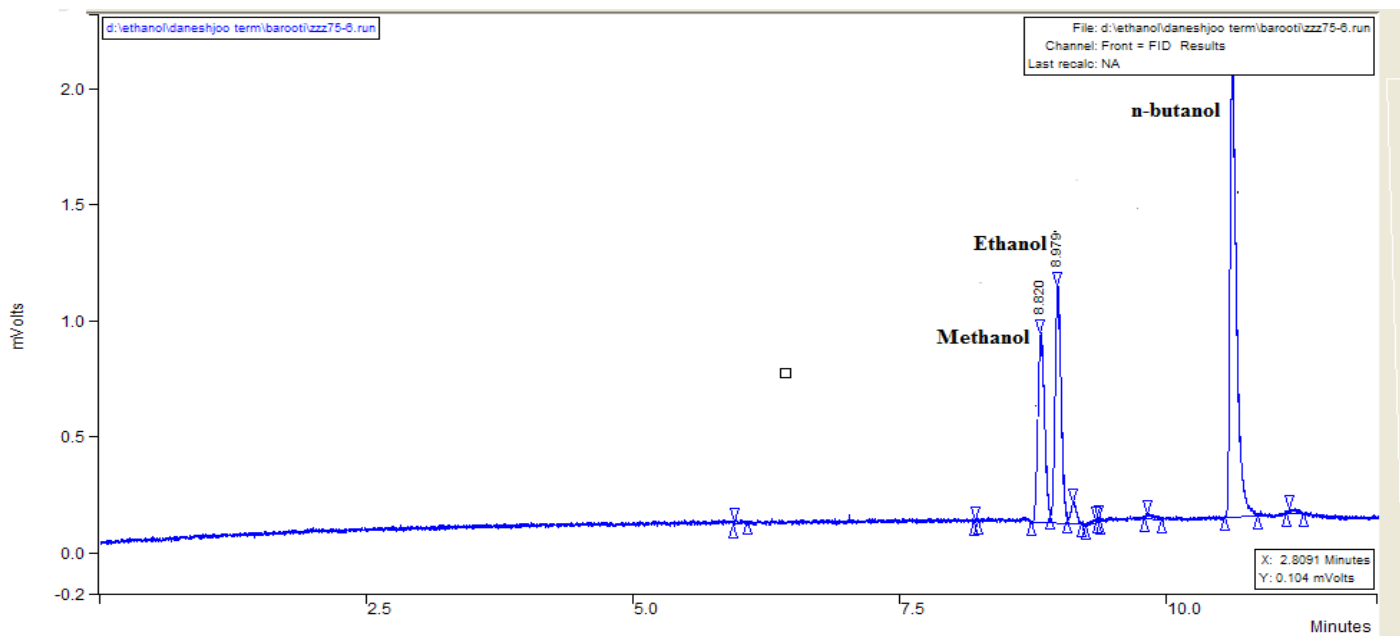

Figure 1 Typical GC-PFPD chromatogram of methanol, ethanol, and n-butanol detected in standard mixture.

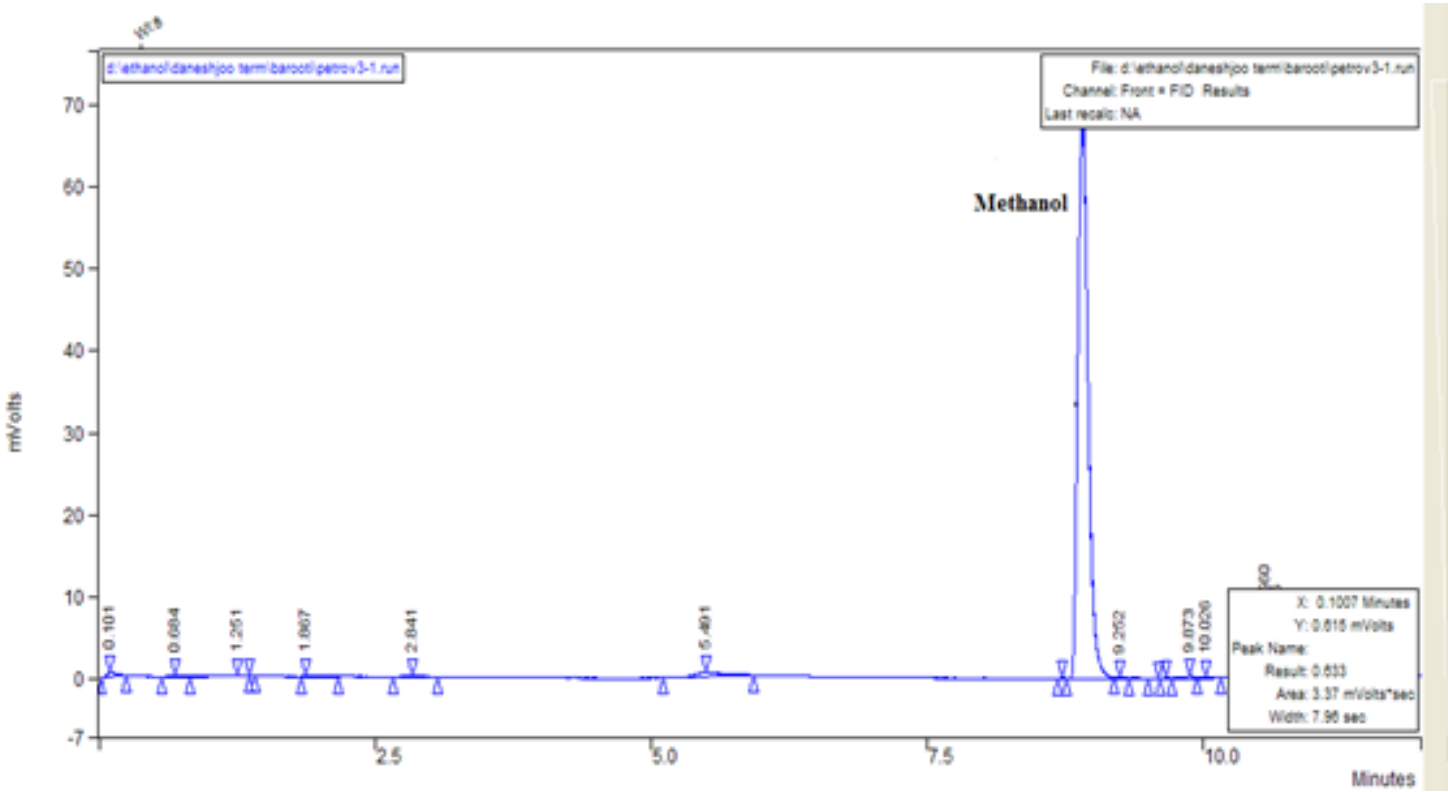

Figure 2 Figure 2 GC-PFPD chromatogram of methanol in Petrovich brand (malt flavor). 


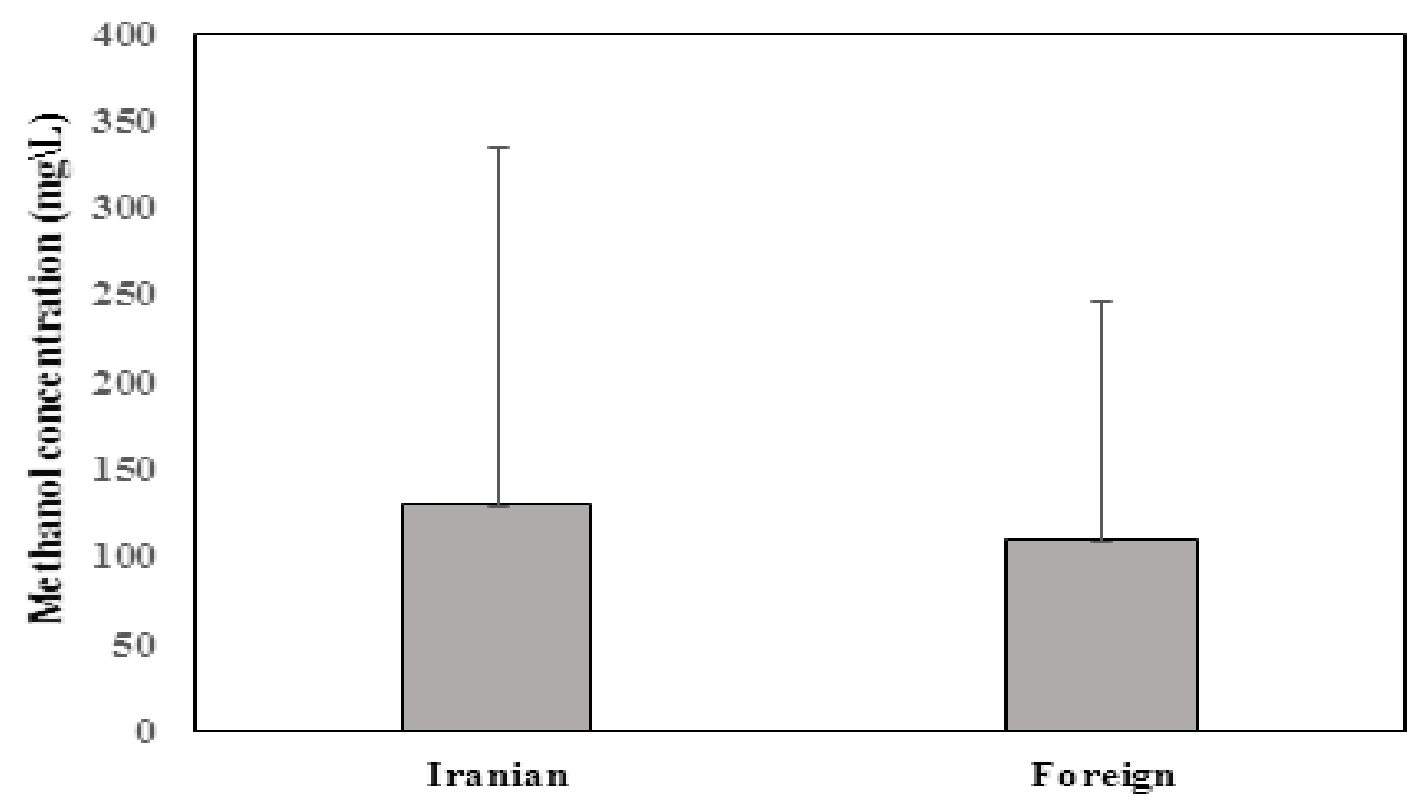

Figure 3 Comparison of methanol concentration between Iranian and foreign Ma-al-shaeer brands. Data are mean $\pm \mathrm{SD}(\mathrm{n}=9)$.

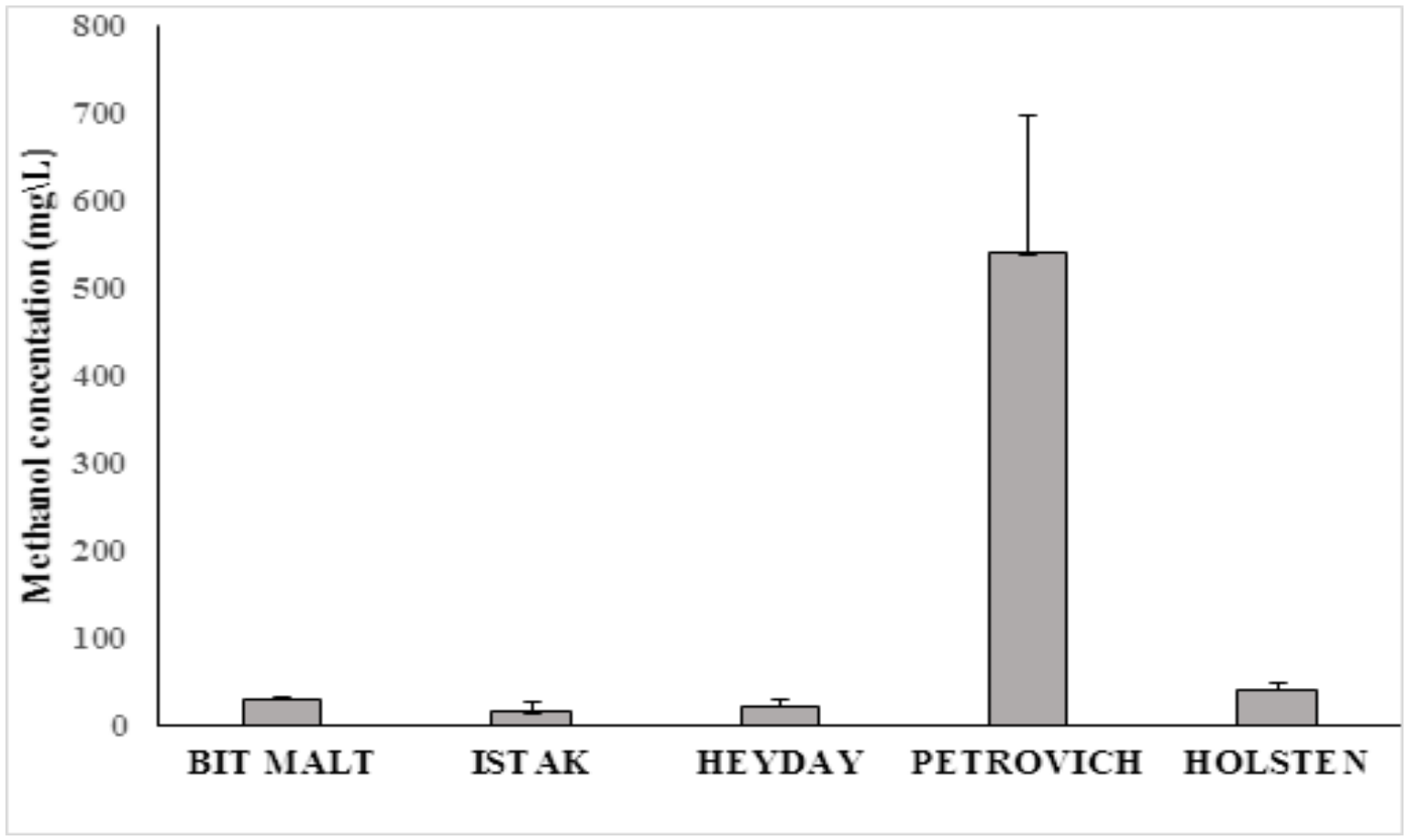

Figure 4 Comparison of methanol concentration among different Iranian Ma-al-shaeer brands. Data are mean \pm SD $(n=9)$. 


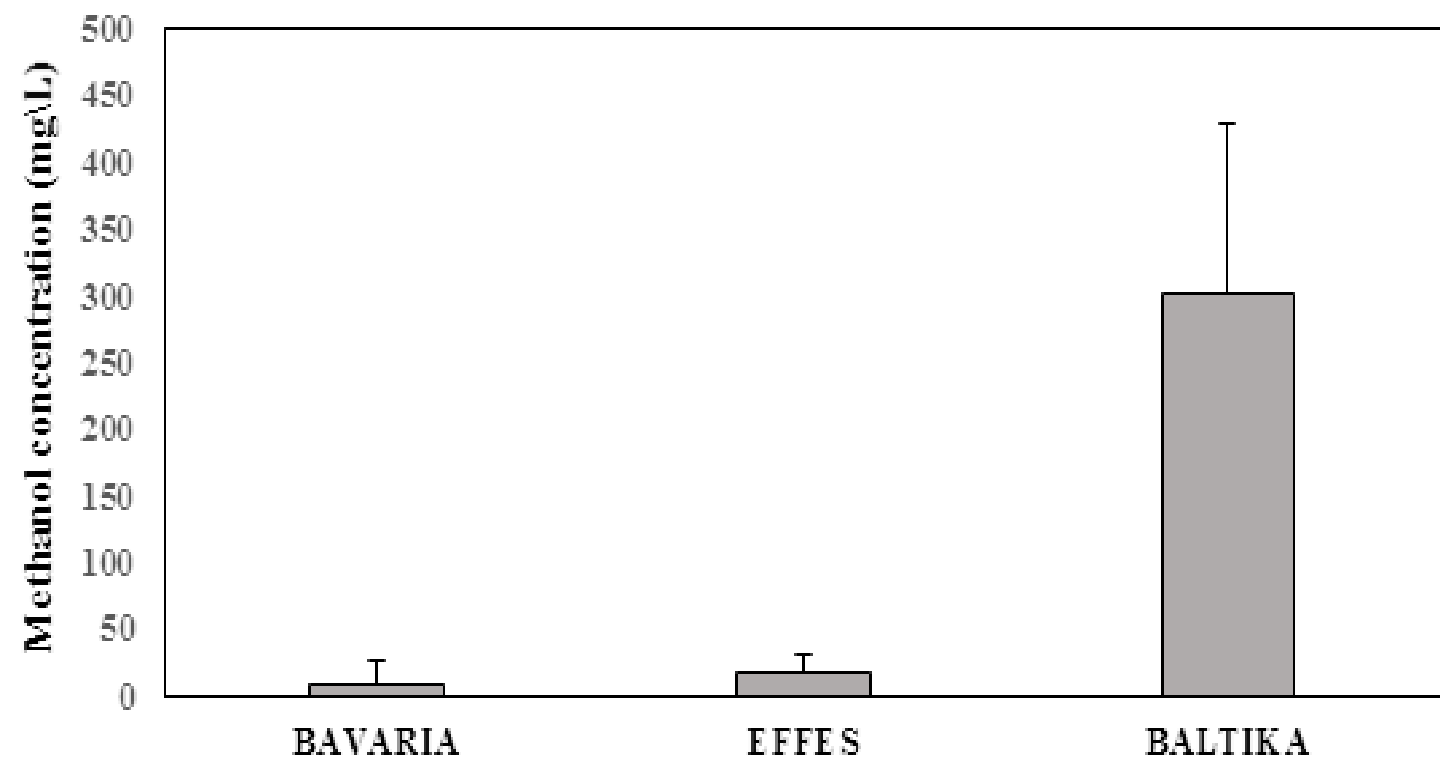

Figure 5 Comparison of methanol concentration among different foreign Ma-al-shaeer brands. Data are mean \pm SD $(\mathrm{n}=9)$. 
symptoms such as optic nerve damage, diarrhea, abdominal pain, hypotension, and anion gap. Metabolic acidosis, seizures, and coma are associated with blood methanol concentration above $500 \mathrm{mg} / \mathrm{L}$ Concentration above 1500$2000 \mathrm{mg} / \mathrm{L}$ will result in death. Owing to its major toxicity, quality control of Ma-al-shaeer products is greatly recommended.

\section{Conclusion}

Using Eq. (1), EDI of methanol for Iranian people through consumption of Ma-al-shaeer was determined $0.023 \mathrm{mg}$ / $\mathrm{kg}$ bw/day. In regard to TDI of methanol (20 mg/kg bw/ day), it is clear that methanol concentration in Ma-alshaeer brands was much lower than its TDI value (25). It was assumed that all Iranian people were used mentioned brands. Our finding revealed that there is no health risk to methanol by Ma-al-shaeer consumption.

\section{Acknowledgment}

The results described in this study were part of a Pharm.D. Thesis. The authors are thankful to the Vice Chancellor of Research, Mashhad University of Medical Sciences, for financial support.

\section{Conflict of interest}

The authors declare that there are no conflicts of interest.

\section{References}

1. Sohrabvandi S, Mousavi S, Razavi S, Malganji S, Khosravi-Darani K, Mortazavian A. The effect of Saccharomyces strain and fermentation conditions on production of Ma-al-Shaeer. Iranian J Nutr Sci Food Technol. 2013;8(3):179-187.

2. Buzrul S. A suitable model of microbial survival curves for beer pasteurization. LWT-Food Sci Technol. 2007;40(8):1330-1336.

3. Bamforth CW. Nutritional aspects of beer- a review. Nutr Res. 2002;22(1):227-237.

4. Fantozzi P, Montanari L, Mancini F, Gasbarrini A, Addolorato G, Simoncini $\mathrm{M}$, et al. In vitroantioxidant capacity from wort to beer. LWT-Food Sci Tech. 1998;31(3):221-227.

5. Ghiselli A, Natella F, Guidi A, Montanari L, Fantozzi P, Scaccini C. Beer increases plasma antioxidant capacity in humans. J Nutr Biochem. 2000;11(2):76-80.

6. Gorinstein S, Caspi A, Zemser M, Trakhtenberg S. Comparative contents of some phenolics in beer, red and white wines. Nutr Res. 2000;20(1):131-139.

7. Nardini M, Ghiselli A. Determination of free and bound phenolic acids in beer. Food Chem. 2004;84(1):137-143.

8. Franco L, Galán C, Bravo R, Bejarano I, Peñas-Lledo E, Rodríguez A, et al. Effect of non-alcohol beer on anxiety: Relationship of 5-HIAA. J Neurochem. 2015;9(2):149-152.

9. Franco L, Sánchez C, Bravo R, Rodríguez AB, Barri- ga C, Romero E, et al. The sedative effect of non-alcoholic beer in healthy female nurses. PloS one. 2012;7(7):e37290.

10. Malganji S, Jalilvand A, Sohrabvandi S. Effects of fermentation temperature and two Saccharomyces yeasts on non-alcoholic Ma-al-shaeer properties. Iranian J Nutr Sci Food Technol. 2013;7(5):335-343.

11. Huige NJ, Sanchez GW, Leidig AR. Process for preparing a nonalcoholic (less the 0.5 volume percent alcohol) malt beverage. Google Patents; 1990.

12. Jammalamadaka D, Raissi S. Ethylene glycol, methanol and isopropyl alcohol intoxication. Am J Med Sci. 2010;339(3):276-281.

13. O'Keefe JH, Bhatti SK, Bajwa A, DiNicolantonio JJ, Lavie CJ. Alcohol and cardiovascular health: the dose makes the poison... or the remedy. Mayo Clin Proc; 2014.

14. Al-Ansari B, Thow AM, Day CA, Conigrave KM. Extent of alcohol prohibition in civil policy in Muslim majority countries: the impact of globalization. Addiction; 2015.

15. Abu-Ras W, Ahmed S, Arfken CL. Alcohol use among US Muslim college students: Risk and protective factors. J Ethn Subst Abuse. 2010;9(3):206-220.

16. Nejabat M, Kahe H, Shirani K, Ghorbannezhad P, Hadizadeh F, Karimi G. Health risk assessment of heavy metals via dietary intake of wheat in Golestan Province, Iran. Hum Ecol Risk Assess; 2017.

17. Sohrabvandi S, Razavi SH, Mousavi SM, Mortazavian A, Rezaei K. Application of Saccharomyces rouxii for the production of non-alcoholic beer. Food Sci Biotechnol. 2009;18(5):1132-1137.

18. Maleki R, Farhadi K, Tahmasebi R. Preparation of a sol-gel titania based coating for HS-SPME of aliphatic alcohols from non-alcoholic beer samples. Chromatographia. 2009;69(7-8):775-778.

19. Morad A, Hikal A, Buchanin R. Gas-liquid chromatographic determination of ethanol in "Alcohol-Free" beverages and fruit juices. Chromatographia. 1980;13(3):161-163.

20. James JT. Spacecraft maximum allowable concentrations for airborne contaminants; 2008.

21. Shirani K, Hassani FV, Azar-Khiavi KR, Moghaddam ZS, Karimi G. Determination of methanol in Iranian herbal distillates. J Complement Integr Med. 2016;13(2):123127.

22. Possner D, Zimmer T, Kürbel P, Dietrich H. Methanol contents of fruit juices and smoothies in comparison to fruits and a simple method for the determination thereof. Deut Lebensm Rundsch. 2014;110(2):65-59.

23. Karimi G, Hassanzadeh M, Shahidi N, Samie Z. Quantitative determination of methanol in plant water produced in Mashhad by spectrophotometry method. J Med Plan. 2008;1(25):56-59.

24. Wu M-C, Jiang C-M, Ho Y-Y, Shen S-C, Chang H-M. Convenient quantification of methanol in juices by methanol oxidase in combination with basic fuchsin. Food Chem. 2007;100(1):412-418.

25. Lachenmeier DW, Schoeberl K, Kanteres F, Kuballa T, Sohnius EM, Rehm J. Is contaminated unrecorded alcohol a health problem in the European Union? A review of existing and methodological outline for future studies. Addiction. 2011;106(s1):20-30. 